\title{
Herbert Somerton Foxwell e a tradição econômica de Cambridge *
}

\author{
Rogério Arthmar **
}

\begin{abstract}
Resumo
O artigo resgata o aporte de Herbert Somerton Foxwell à formação da abordagem econômica de Cambridge, na Inglaterra, durante a sua longa estadia como professor na instituição no final do século dezenove e as primeiras décadas do século vinte. Inicialmente, apresentam-se algumas notas biográficas a respeito do autor em suas atividades acadêmicas e na aquisição de livros. A seguir, delineia-se a sua associação com o movimento historicista inglês, bem como a produção intelectual de Foxwell nos campos da economia bancária, da concorrência, das flutuações industriais e da história do pensamento econômico. Simultaneamente, em cada seção, ilustra-se a sua influência na obra de colegas como John Neville Keynes, John Maynard Keynes, Piero Sraffa e Arthur Cecil Pigou. $\mathrm{O}$ artigo encerra com algumas considerações sobre os avanços e limitações da participação de Foxwell nas controvérsias econômicas de seu tempo.
\end{abstract}

Palavras-chave: Movimento historicista; Sistema bancário; Monopólios; Emprego; História do pensamento econômico.

\section{Abstract \\ Herbert Somerton Foxwell and the Cambridge economic tradition}

This paper looks back at Herbert Somerton Foxwell's influence on the constitution of Cambridge's approach to economics during the many years in which he served as fellow of the institution in the late nineteenth and early twentieth centuries. We begin by providing some biographical notes on his academic and book collecting activities. After that, Foxwell's association with the English historical movement, as well as his intellectual legacy to the economics of banking, industrial fluctuations and the history of economic thought are outlined. At the same time, his influence on the works of his colleagues John Neville Keynes, John Maynard Keynes, Piero Sraffa and Arthur Cecil Pigou is illustrated in each section. The paper concludes with some remarks on the strengths and limitations of Foxwell's contribution to the economic controversies of his time.

Keywords: Historicist movement; Banking; Monopolies; Employment; History of economic thought. JEL B10, B13, B25, E12, L11.

\section{Introdução}

Nas últimas décadas do século dezenove, a doutrina liberal forjada pelos antigos economistas clássicos tornou-se objeto de substancial revisão na Inglaterra, refletindo o avanço nos movimentos socialista, historicista e idealista que denunciavam não somente as iniquidades advindas da distribuição injusta da riqueza, como também a negligência de tal realidade pelas especulações abstratas da economia política clássica (Boucher, 1997, p. 95-214; Claeys, 1987,

* Artigo recebido em 8 de julho de 2018 e aprovado em 16 de setembro de 2018. As traduções do texto são de responsabilidade do autor que agradece as valiosas sugestões de Laura Valladão de Mattos, Mauro Boianovsky e de um parecerista anônimo desta revista, bem como o apoio do CNPq, bolsa n. 305168/2015-0.

** Professor dos Programas de Pós-Graduação em Economia e em História da Universidade Federal do Espírito Santo (UFES), Vitória, ES, Brasil. E-mail: rogerio.arthmar@ufes.br. ORCID: https://orcid.org/0000-0001-7085-2645. 
p. 130-195; Freeden, 1986, p. 25-75). Na universidade de Cambridge, ao longo de boa parte do século vinte, os acadêmicos buscaram estabelecer uma tradição de estudos sobre o bem-estar resultante da combinação entre o utilitarismo maduro e a abordagem marginalista, acompanhada de certa dose de ética, história e, ocasionalmente, epistemologia (Arthmar; McLure, 2017, p. 51-71; Backhouse; Nishizawa, 2010, p. 1-14). A produção intelectual que daí emergiu focava essencialmente nas falhas e nos efeitos não contabilizados dos mecanismos de mercado, com atenção especial às formas pelas quais essas deficiências poderiam ser corrigidas (Groenewegen, 1995, p. 302-342, p. 531-569; Maloney, 1991, p. 165-185).

Para tal fim, os economistas de Cambridge direcionaram a sua abordagem ao estudo das limitações do sistema competitivo propugnado por seus antecessores. Como descrito por Hla Myint (1948, p. 123): "Nisso, eles efetivamente romperam com a hipótese clássica de uma harmonia econômica geral ao apontarem situações concretas de exceção nas quais o laissezfaire conduziria a um conflito entre os interesses social e privado e, consequentemente, a uma perda de bem-estar". Mais recentemente, Geoffrey Harcourt definiu o estilo peculiar de pensar a economia em Cambridge desde quando se instituíram os Economic Tripos por Alfred Marshall, em 1903, até a aposentadoria dos pupilos de John Maynard Keynes, nos anos de 1980, da seguinte forma: "A abordagem de Cambridge para a economia aplicada enfatiza as limitações da teoria neoclássica ortodoxa [...] e confere importância ao que é relevante em economia, incorporando as lições da história, do contexto institucional e das condições sociais e políticas prevalecentes" (Harcourt, 2012 [2007], p. 232).

Papel essencial na constituição da moderna perspectiva econômica de Cambridge, juntamente com Marshall, embora raramente lembrado, coube a Herbert Somerton Foxwell (1849-1936) ${ }^{1}$. Tendo assumido como professor no Saint John's College em 1874, com idade de 25 anos, no ano seguinte foi indicado examinador dos Tripos de Ciências Morais. Ele permaneceria associado a Cambridge por mais de seis décadas. Foxwell ensinou ainda no University College, onde iniciou em 1876, assumindo em 1881 a cátedra que pertencera ao amigo William Stanley Jevons, e em 1896 passou a lecionar sobre moeda e bancos na recémcriada London School of Economics. A respeito de seus atributos na função de educador, Foxwell era admirado como profissional de índole extremamente prática, invariavelmente preocupado com os temas correntes de economia. John Maynard Keynes, em seu obituário do colega, descreveu o estilo de lecionar do amigo como invariavelmente direcionado a problemas práticos a partir de uma ótica realista: "[E]le defendia que o raciocínio econômico, para ser frutífero, deve ser aplicado a uma grande variedade de fatos fornecidos pela história e pela

(1) Foxwell nasceu em Shepton Mallet, paróquia civil do distrito Mendip, em Somerset, região sudeste da Inglaterra, no dia 17 de junho de 1849, o mais velho de seis irmãos do casal Thomas Somerton Foxwell (1806-1866) e Jane Handcock (18241878), sua segunda esposa. O pai de Foxwell era um mercador bem-sucedido de materiais de construção, embora grande parte de sua fortuna tenha sido perdida com a crise do banco Overend Gurney em 1866. O infante Foxwell recebeu educação inicial no lar, mais tarde sendo matriculado no Wesleyan Collegiate Institute, atualmente Queen's College, de Taunton, graduando-se na London University em 1868. Nesse mesmo ano ingressou no Saint John's College, em Cambridge, como estudante de ciências morais, tendo recebido a bolsa Whewell em Direito Internacional em 1872 (Bowley, 2004; Koot, 1977; Bonar, 1936). 
experiência contemporânea, e não apenas direcionado à construção de hipóteses simplificadas e artificiais" (Keynes, 1936b, p. 592).

O traço mais conspícuo da vida científica de Foxwell, pelo qual se tornou merecedor da eterna gratidão dos economistas, residiu na sua obstinação ímpar em compilar uma bibliografia praticamente completa de economia. Colecionador inveterado, Foxwell não apenas procurava sem descanso os livros, panfletos e tratados que lhe interessavam; ele os lia, anotava e catalogava cada um deles, prática que, com o tempo, tornou-o especialista na história do pensamento econômico de ampla gama de assuntos desde o século dezessete. Sua primeira grande coleção, possuindo em torno de 30 mil livros, esteve a ponto de ser vendida a uma biblioteca norte-americana quando, após apelo público por parte da British Economic Association, veio ela a ser adquirida pela Goldsmiths' Company em 1901 e, em 1903, doada à London University. Nas palavras do próprio Foxwell, a coleção destinava-se "a servir de base para o estudo da história industrial, comercial, monetária e financeira do Reino Unido, bem como do gradual desenvolvimento da ciência [econômica] em geral" (Foxwell, 1908, p. 720)2.

Embora tenha se destacado como professor e colecionador, as constantes viagens e o tempo consumido na execução de tais tarefas fizeram de Foxwell um escritor errático. Sua obra, composta por conferências, artigos e introdução a livros contém, no entanto, uma combinação de erudição, arrojo e heresia que, nos termos de seu contemporâneo Joseph S. Nicholson, professor de economia em Edimburgo, soava como se ele estivesse a reviver "o espírito dos antigos autores panfletários" (Nicholson, 1919, p. 323). Destarte a multiplicidade de assuntos tratados nos escritos de Foxwell, seu interesse maior gravitava em torno de quatro tópicos principais, a saber: a importância do método histórico na economia; os problemas bancários e monetários; a instabilidade do regime de concorrência e seus efeitos sobre o emprego e, finalmente, a história do pensamento econômico. Sua contribuição a cada um desses campos, em seus traços essenciais, será examinada no restante deste trabalho na ordem indicada, apontando ainda, de forma breve, o seu impacto nos escritos de economistas contemporâneos de Cambridge como John Neville Keynes, John Maynard Keynes, Piero Sraffa e Arthur Cecil Pigou.

\section{Foxwell e o movimento historicista na Inglaterra}

Quando Foxwell assumiu as suas atividades letivas em Cambridge, a economia política britânica atravessava período de grande comoção. De uma parte, Jevons propunha abordagem mais rigorosa da ciência, enquanto atacava sem mercê David Ricardo e John Stuart Mill por, segundo ele, "haverem desviado o carro da economia para um caminho equivocado" (Jevons, 1871 , p. 1). De outra parte, o desconexo, mas altamente vocal movimento historicista na Inglaterra, liderado por William Cunningham (1849-1919), John Kells Ingram (1823-1907) e Thomas Edward Cliffe Leslie (1825-1882), entre outros, empreendia feroz ofensiva aos

(2) Foxwell reuniria ainda outra coleção, vendida a Harvard University, em 1929, que veio a constituir a base da atual Kress Library of Business and Economics naquela instituição (Rogers, 1986; Keynes, 1936). 
Rogério Arthmar

fundamentos da ortodoxia clássica e, por vezes, até mesmo aos da emergente escola neoclássica. Os historicistas investiram, primeiramente, contra o limitado escopo da economia política, urgindo que a ciência levasse em consideração os fatores sociais que tanto relevo detinham noutros campos do conhecimento como a sociologia, a biologia e a moral. Em segundo lugar, condenaram o estilo peculiar de raciocínio ricardiano - puramente abstrato e fundado no interesse individual -, por desconsiderar os motivos não econômicos dos indivíduos, bem como a condição perene de mudança da sociedade. Finalmente, argumentaram que a economia política deveria apresentar orientação mais prática, investigando de maneira sistemática questões de natureza aplicada (Koot, 1977; Schumpeter, 1963, p. 821-824; Coats, 1954). Cunningham, professor em Cambridge entre 1884 e 1897, escrevendo sobre os aspectos morais da economia política, advertiu que os fenômenos ligados a esse campo do conhecimento deveriam ser interpretados não como obra de um só fator, mas sim, como resultantes da ação de forças qualitativamente distintas.

A economia política tem sido uma ciência das coisas e discorrido sobre o seu valor intrínseco; tem sido a ciência do mecanismo e explicado a interação entre interesses competitivos; não devemos nós tratá-la como uma ciência moral, que considera os recursos da natureza humana para a satisfação das necessidades humanas? A economia política tem a ver com tais recursos -as atividades e capacidades- da natureza humana empregada no atendimento de suas necessidades. [...] Se esta abordagem de nosso objeto lhe retira o egoísmo, ela também concede à ciência maior proximidade com a vida real, tanto passada quanto futura (Cunningham, 1878, p. 373).

Foxwell, de sua parte, não era adversário incondicional do pensamento teórico em si, como será visto adiante, embora se mostrasse extremamente simpático aos preceitos da corrente historicista. No importante artigo The Economic Movement in England, de 1887, ele inicia traçando um quadro estilizado, em tom acusatório, da escola clássica, censurando-a por sua defesa de uma doutrina estritamente materialista, pelo sacrifício do interesse nacional à riqueza individual e, além disso, por se basear completamente em leis imutáveis de teor egoísta ao descrever a natureza humana. Esse tipo de abordagem restritiva, assinala Foxwell, não poderia deixar de despertar a oposição das melhores mentes nos círculos literários, artísticos e espirituais, desmoralizando a ciência econômica em diversos ambientes cultos. Mais importante do que isso, a crença irrestrita no poder das forças competitivas já teria se tornado obsoleta pelo advento de uma realidade histórica distinta, marcada pela ascensão da classe trabalhadora, pelo fim do período de prosperidade do século dezenove, bem como pela profunda reorganização da indústria mundial rumo a uma nova fase monopolista (Foxwell, 1887).

No plano intelectual, três fatores, segundo Foxwell, teriam ocasionado o declínio da antiga doutrina do laissez-faire. O primeiro residiria no surgimento de uma abordagem verdadeiramente científica da economia, inaugurada por Jevons e aperfeiçoada por Marshall, caracterizada pelo uso da matemática no raciocínio econômico, a exatidão das definições e a delimitação precisa das fronteiras entre a teoria e a realidade. $\mathrm{O}$ segundo fator consistiria no avanço da abordagem histórica na Inglaterra, promovida pela obra de pensadores como Cliffe 
Leslie, pelas descobertas das implicações sociais da biologia evolucionária e, ainda, pelo advento da filosofia histórica alemã. Ao descrever essa nova perspectiva da dinâmica social, observou Foxwell:

Em geral, pode-se dizer que enquanto a antiga escola de economistas contentava-se em deduzir, de forma mais ou menos desconexa as consequências de um dado conjunto de premissas -parcialmente ideal, mas admitidas como correspondente aos fatos e instituições da época, sendo, em certo sentido, natural ou comum à todas as épocas-, a nova escola tem, comparativamente, parco interesse em deduções por acreditar que os fatos não foram ainda cuidadosamente observados; que as hipóteses guardam apenas relação remota com os fatos; que os fatos em si encontram-se em processo de evolução e mudança, e que a natureza e direção dessa transformação social são muito mais importantes do que elaboradas e complicadas deduções, frágeis para uso prático no tocante à ação de forças econômicas em um estado particular de evolução. Segue-se que os autores da escola histórica são fortemente antidoutrinários, opondo-se ao dogmatismo arrogante e universal apoiado em um raciocínio primário e com limitada base empírica (Foxwell, 1887, p. 89).

O último fator de declínio da escola clássica devia-se, conforme o professor, ao ressurgimento do antigo espírito humanista britânico, o qual se mostrara tão ativo contra a escravidão e a favor das leis fabris, e que agora se erguia novamente contra o ímpeto materialista dos tempos, propugnado pela doutrina econômica de inspiração ricardiana. Foxwell, contudo, mostra-se célere ao minimizar qualquer possibilidade de atrito entre as diversas visões contemporâneas do verdadeiro objeto da economia, propondo, ao contrário, uma aliança estratégica entre as escolas dos moralistas, dos historicistas e dos marginalistas. Tal associação deveria ser construída sobre a divisão tácita do conhecimento econômico em compartimentos, ou seja, pela definição de limites precisos a cada abordagem no interior da ciência econômica. "Se o teórico, o historiador e o moralista mantiverem-se estritamente dentro das fronteiras de suas investigações, eles se ajudarão em vez de conflitarem entre si" (Foxwell, 1887, p. 91).

O aspecto interessante a ser observado neste ponto é que Foxwell antecipa essencialmente a mesma solução divisada pouco depois por seu colega de Cambridge, John Neville Keynes, em sua famosa obra The Scope and Method of Political Economy (1890), para o estado geral de dissensão que dominava a economia da época. O livro propunha uma separação clara entre os diferentes campos de estudo da ciência como o remédio mais eficaz para as disputas metodológicas. Dito doutra forma, a economia "positiva", como imaginada por Neville Keynes, envolveria o conhecimento sistematizado daquilo que existe ou o corpo teórico da ciência; a economia "normativa" estaria ligada aos critérios do que deve ser, ou da situação concreta a ser implementada e, por fim, a economia como "arte" compreenderia o sistema de regras para a consecução de determinados objetivos. Ao comentar a confusão frequente entre proposições teóricas, considerações morais e prescrições de política econômica, recomendou ele: "Noutras palavras, as pesquisas teóricas e práticas não devem ser sistematicamente misturadas, ou assimiladas uma na outra, como sustentado por aqueles que declaram ser a economia política um todo único de inquirições teóricas e práticas" (J. N. Keynes, 1897 [1890], p. 65). 
Rogério Arthmar

Adiante, John Maynard Keynes, que crescera vizinho à residência de Foxwell, não deixaria de revelar a influência do professor em sua formação teórica ao contestar igualmente o primado da doutrina competitiva clássica entre os economistas. No panfleto The End of Laissez-Faire, de 1926, Keynes sustentou que o princípio liberal se mostrara bem-sucedido no século dezenove, entre outras razões, por sua extrema simplicidade, auxiliado pelas limitações das alternativas ideológicas como o marxismo e o protecionismo. Além disso, o desperdício das Guerras Napoleônicas e a ineficiência geral do Estado colaboraram em grande medida para o sucesso do discurso favorável à parcimônia e à neutralidade fiscal. Por fim, o individualismo e o laissez-faire triunfaram, igualmente, por sua conformidade a visão peculiar do mundo dos negócios. Keynes, todavia, não acreditava na propalada coincidência entre interesses públicos e privados implícita no discurso da ortodoxia liberal, a qual, na sua forma de ver, desconsiderava aspectos fundamentais da realidade econômica moderna como o poder dos monopólios, a incerteza sobre o futuro e o tempo envolvido nos ajustamentos econômicos.

A beleza e simplicidade de tal teoria é tão grande que é fácil negligenciar ser ela deduzida não dos fatos reais, mas de uma hipótese incompleta introduzida com a finalidade de facilitar o raciocínio. À parte outras objeções, a conclusão que os indivíduos, agindo independentemente para sua própria vantagem, produzirão o maior agregado de riqueza depende de uma variedade de suposições irreais de modo que o processo de produção e consumo se torna inorgânico, supondo a existência de suficiente conhecimento prévio das condições e necessidades do mercado (Keynes, 1999 [1926], p. 20).

É oportuno ressaltar aqui igualmente que a disposição incondicional de Foxwell a desabonar Ricardo e seu legado deve ter atuado de alguma forma na dissolução de sua longa amizade com Marshall, haja vista que este último considerava os seus estudos parte da evolução natural da tradição britânica de economia política, além de qualificar Ricardo um pensador inigualado em sua genialidade (Marshall, 1925 [1885], p. 153-155; 1920 [1890], p. 761-763; Shove, 1942). Em 1908, as manobras de Marshall às vésperas da votação para o seu sucessor na cátedra de economia política em Cambridge, asseguraram que o jovem Arthur Cecil Pigou, então com 30 anos, fosse eleito para o posto. Foxwell, o candidato natural já quase sexagenário, sentiu-se traído por Marshall, até então seu dileto amigo, de quem doravante se afastou definitivamente $^{3}$ (Groenewegen, 1995, p. 622-627; Coase, 1972; Coats, 1972). Essa ruptura com aquele que se tornara um dos mais influentes economistas da Inglaterra certamente operou em larga medida no indevido e silencioso esquecimento da contribuição de Foxwell a formação da perspectiva econômica peculiar de Cambridge.

\section{A teoria monetária de Foxwell}

Durante o longo período entre 1860 e 1913, os especialistas em análise monetária estiveram ocupados em discutir, primeiramente, propostas relacionadas à prática do

(3) A votação em favor de Pigou foi unânime pelos membros da Câmara Eleitoral de Cambridge, que preferiram apostar na capacidade do jovem professor em consolidar as conquistas acadêmicas de Marshall, especialmente os Economic Tripos criados em 1903 (Aslanbeigui; Oakes, 2015, p. 21-40). 
bimetalismo, as quais experimentaram certa voga em países como os Estados Unidos e França; em segundo lugar, o uso da taxa de desconto dos bancos centrais como meio de se atingir objetivos monetários e, finalmente, a forma mais apropriada de se debelar pânicos financeiros. Tais questões conectavam-se, direta ou indiretamente, ao tema relativo à conveniência de uma economia nacional possuir oferta monetária elástica capaz de debelar crises de liquidez e atender, ao mesmo tempo, as necessidades legítimas do mundo comercial com base em uma unidade monetária estável (Mints, 1945, p. 178-197).

Foxwell cultivava posições bem definidas a respeito do papel dos bancos no sistema econômico. O tema é analisado em seu artigo de 1917 The Financing of Industry and Trade, publicado como capítulo III do livro Papers on Current Finance (1919), onde afirma ele constituir-se o principal desafio dos tempos modernos a provisão de meios suficientes para facilitar a consolidação das grandes corporações. Embora Foxwell entendesse como tarefa precípua dos bancos a provisão de recursos financeiros às firmas produtivas, ele lembra que, historicamente, as casas bancárias britânicas haviam se especializado num tipo peculiar de operações. Diferentemente dos bancos comerciais continentais, sujeitos a regulações menos estritas no tocante às suas reservas e que, por essa razão, mostravam-se mais dispostos a embarcar no financiamento de grandes empreendimentos industriais, as instituições financeiras britânicas não ocultavam a sua preferência por empréstimos de curto prazo, em conexão com a Bolsa de Valores e o mercado de títulos privados, ou mesmo em negócios com o exterior. A desafortunada consequência de tal situação, lamenta Foxwell, manifestava-se na circunstância de que a indústria e o comércio nacional precisavam sobreviver sem qualquer financiamento de longo prazo por parte dos bancos britânicos. Tendo em vista que as instituições continentais exerciam interação mais ativa com os empreendimentos industriais de seus países, tal contraste significava que a Inglaterra terminaria em posição retardatária na competição internacional por novos mercados e pelo uso de novas tecnologias, enquanto a indústria doméstica padecia por falta de capital líquido adequado.

A perda para nossa indústria é por demais óbvia. Ela não pode obter dos bancos os meios de efetivar a modernização de suas instalações, ou as extensões e reconstruções requeridas pelo progresso da técnica industrial, ou pelos desenvolvimentos de firmas rivais de outras nações; tampouco aqueles empréstimos vultosos que, na prática, revelam-se essenciais à obtenção de grandes contratos no exterior (Foxwell, 1919a [1917], p. 128).

Com respeito ao funcionamento do sistema bancário britânico sob o regime de padrãoouro durante o período anterior à I Guerra Mundial, diversas vozes propugnavam a reforma do Bank Act de 1844 que estabelecera âmbito limitado à ação discricionária do Banco da Inglaterra. ${ }^{4}$ A preocupação principal dos banqueiros e industriais concentrava-se no reduzido

(4) O Bank Charter Act de 1844, promulgado pelo Primeiro Ministro Robert Peel, conferia ao Banco da Inglaterra exclusividade na emissão de notas bancárias na Inglaterra e no País de Gales, em detrimento dos demais bancos. O ato condicionava a emissão de novas notas, além daquelas já em circulação, à sua cobertura integral em ouro nas reservas da instituição. O Banco da Inglaterra, conjuntamente, foi dividido nos departamentos de emissão (Issue Department) e de atividades financeiras (Banking Department) (Andréadès, 1909, p. 285-293, p. 411-416). 
volume das reservas áureas do Banco, assim como na frequência e intensidade das alterações na sua taxa de desconto visando proteger o modesto acervo de ouro da instituição (Hume, 1970, p. 127-133). Foxwell, no artigo de 1909 The Bank Reserve, mostrou-se particularmente alarmado pelo fato de que, enquanto os bancos continentais reforçavam suas posses do metal, a situação no país permanecera inalterada, registrando apenas ligeiro aumento no estoque correspondente abrigado no Banco da Inglaterra. Um dos efeitos negativos de tal quadro refletia-se na extrema sensibilidade da taxa de desconto do Banco em resposta à ligeiras mudanças de suas reservas. E, dado o volume substancial de depósitos estrangeiros nas casas bancárias de Londres, o sistema financeiro nacional se encontrava, portanto, demasiadamente exposto à rápidas e imprevistas turbulências financeiras que, por intermédio de seus efeitos no custo do dinheiro, impunham pesado ônus aos negócios domésticos, afetando negativamente o volume de emprego. "Existem numerosas pessoas hoje que poderiam mover um milhão ou muitos milhões de ouro se eles assim decidissem fazê-lo. É correto que nosso comércio seja exposto a um tributo dessa natureza por obra dessas operações ocasionais?" (Foxwell, 1919a [1909], p. 155).

No prefácio ao livro de Andreas M. Andréadès, History of the Bank of England, publicado em 1909, Foxwell louva a instituição por conferir precedência à estabilidade da economia doméstica em detrimento da conversibilidade em ouro da esterlina durante as Guerras Napoleônicas (1793-1815). ${ }^{5}$ Aqui, a intolerância de Foxwell com Ricardo reemerge por inteiro, haja vista que este último, em seu panfleto de 1809, The High Price of Bullion, criticara o Banco pelo excesso de emissão fiduciária nos anos de restrição da conversibilidade. Ricardo caracterizara o comportamento da instituição como a causa última da depreciação da libra esterlina nos mercados cambiais e do aumento no preço do ouro, processo que haveria criado uma pressão inflacionária que ele condenava nos termos mais veementes ${ }^{6}$. Foxwell, após desabonar Ricardo e os seus seguidores "doutrinários" no que concerne a esse ponto, congratula o Banco e seus diretores por terem guiado o país através de um período extremamente conturbado sem, contudo, comprometer a saúde da economia britânica a fim tão somente de eliminar o ágio no preço do ouro.

Se numa época de perturbação tão excepcional dos negócios o Banco tivesse seguido o conselho dos doutrinários, todo o sistema de financiamento do esforço de guerra teria sofrido colapso. [...] Sem dúvida o Banco mostrou o defeito de suas qualidades; ele pode

(5) Em 3 de maio de 1797, o governo de William Pitt (The Younger), decretou o Bank Restriction Act, dispensando o Banco da Inglaterra do compromisso de converter suas notas em ouro. A emissão excessiva dessas notas pela instituição para acomodar as despesas de guerra do governo havia gerado inflação que comprometera o poder de compra do dinheiro, o qual passara a ser convertido cada vez mais em ouro, esgotando progressivamente as reservas do Banco da Inglaterra. A restrição, prevista para se encerrar em 24 de junho seguinte, foi reeditada inúmeras vezes até 1 de maio de 1821 (Cannan, 1919, p. vii-xvii, p. xxix-xxxiv).

(6) Como reclamou Ricardo: "Que segurança tem o público credor que os juros sobre a dívida pública, agora pagos com dinheiro depreciado em quinze por cento, não possam ser pagos adiante com uma depreciação de cinquenta por cento?" (Ricardo, 2004 [1809], p. 96). A mesma posição, reiterando a necessidade de uma política restritiva por parte do Banco a fim de manter o câmbio estável ressurgiria no relatório do Bullion Committee no ano seguinte (Fetter, 1965, p. 39-43, p. 49-54; o Bullion Report encontra-se reproduzido em Cannan, 1919, p. 1-71). 
ter dado muita ênfase à necessidade de acomodar o comércio do país; mas se assim o fez, seus vícios inclinaram-se para o lado da virtude. A principal dificuldade da instituição localizou-se na sua subserviência ao Estado e no seu empenho, na medida dos seus poderes, de evitar pressões desnecessárias sobre a comunidade comercial. Estas são as finalidades para as quais um Banco Nacional existe (Foxwell, 1909, p. xix, xxii).

Uma série de medidas voltadas a prover o sistema bancário com uma reserva mais robusta de ouro e a conferir maior elasticidade à oferta monetária já havia sido concebida por Foxwell no artigo The Bank Reserve. Primeiramente, ele propôs maior transparência e publicidade das estatísticas bancárias, incluindo as reservas áureas do Banco da Inglaterra, por entender que tal prática não apenas refrearia a especulação como também permitiria ao público o exercício de controle mais estrito das instituições financeiras do país. Em complemento, deveria ser constituída uma segunda grande reserva privada, no montante de 25 milhões de libras, mantida por contribuições dos bancos particulares, a ser mobilizada pelo Banco da Inglaterra em tempos de crise financeira, mas sob condição do pagamento de uma taxa de juros progressiva a cada parcela de cinco milhões de libras utilizadas. Finalmente, o governo deveria erigir uma reserva própria de dez milhões de libras a fim de amparar as instituições de poupança no caso de uma corrida emergencial aos depósitos em caso de conflagração internacional (Foxwell, 1909, p. 160-170). A esse respeito, em artigo de 1895 intitulado A criticism of Lord Farrer on the monetary standard, Foxwell adiantou a proposta de restauração do bimetalismo em escala internacional a fim de neutralizar a tendência deflacionária do sistema de padrãoouro, uma vez que a oferta de prata estaria crescendo de forma ininterrupta com preço estável, diferentemente da cotação do ouro que experimentava oscilações contínuas e significativas (Foxwell, 1895, p. 4-6).

A admissão de uma política monetária ativa em tempos de dificuldade econômica advogada por Foxwell deve ter se mostrado deveras atrativa a Keynes, para quem o restabelecimento do sistema de padrão-ouro por parte da Inglaterra no ano de 1925, com a sobrevalorização da esterlina perante o dólar, representara imenso equívoco do então Ministro do Erário Winston Churchill por privilegiar a estabilidade da moeda em detrimento da produção e do emprego ${ }^{7}$. A fim de sustentar as suas reservas áureas em vista do efeito adverso da medida sobre a balança comercial, o Banco da Inglaterra precisaria restringir o crédito doméstico de modo a ocasionar desemprego e deflação dos salários e preços. Essa seria a única forma de corrigir o desalinhamento da taxa de câmbio da esterlina com o dólar perante o restabelecimento da cotação do pré-guerra, a qual não mais se justificava por conta da diferença

(7) Robert Skidelsky destaca que, juntamente com Marshall, Foxwell foi a personalidade favorita de Keynes entre os economistas contemporâneos (Skidelsky, 1994, p. 412, 694). De sua parte, Keynes sempre insistiu com Foxwell para que esse último sistematizasse as suas ideias monetárias, acionando-o seguidamente também como consultor sobre assuntos ligados ao tema, tanto no tocante ao pensamento clássico quanto à história econômica. Por exemplo, no ano de 1912, em sua função de editor do Economic Journal, Keynes estendeu o seguinte convite ao colega: "Algo que me ocorre e que me agradaria demasiado receber de você seria uma série de artigos a serem publicados regularmente intitulada 'Contribuições a História do Sistema Bancário Inglês', ou coisa do gênero. Já estamos quase desalentados de conseguir uma história monetária completa de sua autoria” (Keynes a Foxwell, 5 de fevereiro de 1912; vejam-se também, por exemplo, as cartas de Keynes números 50, 81 e 265 em Kwansei Gakuin, 2018). 
nos níveis de preços nacionais verificada nos anos de conflito (Keynes, 1933 [1925], p. 254260).

Escrevendo sobre o abandono da conversibilidade pelo país em meio à Grande Depressão, no ano de 1931, Keynes saudou a iniciativa como uma medida indispensável à depreciação da moeda britânica e à retomada de suas exportações. Com isso, melhorariam a economia e o emprego domésticos em desfavor de nações como França e Estados Unidos, agrilhoadas ainda ao já obsoleto regime de lastro metálico da moeda.

Enquanto o padrão-ouro é preservado -o que significa que os preços das mercadorias internacionais devem ser praticamente os mesmos em todos lugares- isso envolvia uma campanha competitiva deflacionária, cada um de nós tentando reduzir os preços mais rapidamente que os demais, num processo que intensificou o desemprego e as perdas industriais em extensão insuportável (Keynes, 1933 [1931], p. 293).

Keynes retornaria ao assunto com maior ênfase na Teoria Geral quando, ao examinar as teses mercantilistas, condenou os seus contemporâneos por esposarem o mandamento de que a política de desconto do Banco da Inglaterra deveria ser estritamente regulada pelo nível das reservas áureas de forma a garantir a paridade da esterlina com o dólar, sem consideração às necessidades do mundo comercial e produtivo. "Sob a influência dessa concepção errônea", anotou Keynes, "a City de Londres desenvolveu [...] a técnica da taxa bancária associada à paridade rígida da taxa de câmbio. Isso significou que o objetivo de manter uma taxa de juros doméstica consistente com o pleno-emprego foi totalmente descartada" (Keynes, 2013 [1936], p. 339).

\section{Concorrência, monopólios e emprego}

Fiel à sua visão particular de qual deveria ser a verdadeira natureza da economia, Foxwell desenvolveu abordagem extremamente realista ao tratar da evolução dos mercados. Em sua interpretação, os economistas clássicos teriam perdido contato com o mundo concreto ao apregoarem os pretensos benefícios de uma concorrência todo-poderosa que já não mais guardava conexão com o seu objeto. Em um artigo sobre as relações do Estado com as grandes empresas, publicado em 1889, Foxwell admitiu que a abolição dos monopólios da época mercantilista, baseados em privilégios e poder político, propiciara o livre curso das forças competitivas na economia britânica. Com a passagem do tempo, porém, essas mesmas forças teriam gestado o crescimento irrestrito de um novo tipo de monopólio, erguido agora sobre as bases das habilidades, possessões e oportunidades (Foxwell, 1919a [1889], p. 264-265).

Concorrência, para Foxwell, significava guerra econômica aberta, tendo por resultado inevitável a sobrevivência do mais forte. Com grande acuidade, indicou que mesmo o usufruto de pequenas vantagens por poucas firmas poderia levá-las a se transformar em um monopólio absoluto, porquanto cada sucesso tornaria o vitorioso mais forte e o perdedor mais fraco. Além disso, os avanços nos transportes, nas comunicações e nas finanças teriam operado em favor da constituição de monopólios em escala internacional. Foxwell admitiu, não obstante, a 
existência de limites econômicos a esse processo, especialmente em virtude das dificuldades de administração de grandes empresas, ao que se sobrepunham as inevitáveis alterações no ambiente geral dos negócios.

Ocorre então constante mudança na situação econômica, proporcionando uma chance aos novos empreendedores. $\mathrm{O}$ rápido progresso da ciência, os incalculáveis caprichos da moda, os hábitos diferentes do público, tudo isso perturba a rotina dos negócios e ajuda a subverter os monopólios. A imperfeição da hereditariedade, por sua vez, coloca um fim ao mais bem-sucedido dos empreendimentos. Um pai pode legar uma propriedade ao filho; trata-se de assunto bem diverso deixar-lhe um negócio (Foxwell, 1919a [1889], p. 266).

As vantagens mais evidentes auferidas pelos monopólios, tal como Foxwell as concebia, compreenderiam as economias de administração, a concentração de conhecimento e habilidades, a eliminação dos pesados custos competitivos - como a publicidade -, e o fim da anarquia industrial. Os consumidores seriam beneficiados com a melhor qualidade dos produtos e preços mais estáveis, enquanto a opinião pública possuiria grande poder sobre as operações dos monopólios, dado que a reputação das firmas deveria sempre se manter acima de qualquer suspeita. Abusos, entretanto, aconteceriam de forma inevitável, como na fixação de preços demasiadamente elevados, gerando lucros excessivos, ou na tirania da empresa sobre os empregados, sem esquecer a prática de corrupção dos agentes públicos para a violação da lei. O interesse geral, todavia, resultaria melhor servido não apenas por meio de intervenção estatal absoluta, mas igualmente via a plena divulgação das informações econômicas, oferecendo à opinião pública o conhecimento necessário para o melhor direcionamento possível das despesas de cada indivíduo. A soberania do consumidor constituir-se-ia a mais poderosa ferramenta, segundo Foxwell, de contenção das ações reprováveis dos monopólios. Sempre que necessário, tal regulação deveria ser exercida por organizações de negócios locais, familiarizadas com os acontecimentos, em vez de por representantes da autoridade central (Foxwell, 1919a [1889], p. 270-275).

Foxwell elaboraria novamente sobre o tema em palestra proferida na Royal Institution, em 19 de abril de 1917, intitulada The nature of the industrial struggle. A concorrência, advertiu ele na ocasião, não deveria ser aceita como um princípio universal, mas como um estado de coisas circunscrito no tempo e espaço. Embora Adam Smith e outros acreditassem tratar-se de um processo justo, a indústria moderna já demonstrara a existência de três formas básicas de competição, a saber: primeiramente, via o esforço por maior eficiência; em segundo lugar, pela busca de lucros a qualquer custo e, por fim, mediante a destruição incondicional dos competidores, tanto no plano doméstico quanto internacional. O primeiro caso, de competição honesta, desdobrar-se-ia inevitavelmente na emergência de um monopólio devido às vantagens obtidas em decorrência das inovações. O segundo e o terceiro casos, de competição desonesta, faziam uso de adulteração, materiais de baixa qualidade, espionagem, corrupção e todo um sortimento de recursos enganosos, conduzindo à sobrevivência não da firma mais apta, mas sim da mais delituosa. Dois códigos de moral, portanto, governariam essas estratégias opostas de atividades competitivas, tendo como desfecho, quase sempre, um tipo de equilíbrio danoso, 
com as práticas fraudulentas comumente sobrepujando as honestas. "Há uma espécie de lei de Gresham operando no mundo dos negócios", disse Foxwell a sua audiência, explicando logo em seguida, "Os melhores homens veem-se constrangidos a degradar os próprios padrões pelo poder irresistível das circunstâncias [...] Essa é a 'lei de ferro' na esfera dos negócios sob competição desregrada" (Foxwell, 1919a [1917], p. 320).

Com vistas a lidar com tal situação, Foxwell indicou a conveniência de uma "Política Nacional de Comércio" voltada à proteção da indústria doméstica contra a agressão externa. Além disso, a iniciativa necessitaria enfrentar igualmente o problema do distanciamento entre a ciência e a produção na Inglaterra, cuja associação encontrava-se já bem avançada nas grandes corporações alemãs. Doutro modo, as firmas britânicas perderiam a dianteira entre as economias industrializadas. Mais uma vez, Foxwell alerta sobre os perigos dos monopólios, tais como a competição predatória auxiliada pelo Estado, acompanhada de todos os tipos de corrupção, e mesmo de conflagrações militares com a finalidade de captura de mercados estrangeiros ou o estabelecimento de empreendimentos coloniais afim de assegurar o suprimento de matérias-primas baratas. Em qualquer dos casos, adverte ele, os efeitos mais perversos das empresas monopolistas poderiam ser minimizados por organizações vinculadas ao Estado. Tais entidades, todavia, deveriam ser geridas por membros voluntários, evitando-se assim a formação de uma estrutura burocrática gigantesca e facilitando-se, por esse expediente, o florescimento dos aspectos positivos da indústria moderna (Foxwell, 1919a [1917], p. 9096). Foxwell julgava-se o primeiro autor a apresentar tal leitura peculiar da realidade da época, haja vista que, segundo ele, a mentalidade britânica encontrava-se inteiramente impregnada pelos supostos benefícios da concorrência.

O sentimento inglês é bem expresso em nossa legislação comum, cujo espírito integral é adverso às combinações por se tratarem de "restrição ao comércio". Mas é longe de dúvida que a competição irrestrita destruiu mais negócios honestos do que todas as combinações do mundo. Mesmo na Inglaterra, a legislação tem se voltado mais a limitar a competição do que o monopólio. A história social do século dezenove tem sido um longo protesto, uma grande reação legislativa, contra os males da livre concorrência. Penso ter sido o primeiro economista de língua inglesa a me expressar em defesa das combinações nos negócios (Foxwell, 1919a [1917], p. 88).

Parece evidente, portanto, que a literatura sobre as limitações da firma representativa de Marshall que emergiu em Cambridge a partir do artigo de Sraffa em 1926 deveu-se, nalguma medida, aos esforços de Foxwell em chamar atenção para a realidade da concentração industrial e dos mercados monopolistas no início do século vinte. ${ }^{8}$ Sraffa, como se sabe, criticou a teoria

(8) Após a sua graduação em 1920 pela Faculdade de Direito de Torino, mais precisamente em abril de 1921, Sraffa iniciou período de pouco mais de um ano de estudos na London School of Economics, onde lecionava Foxwell, de quem se tornou amigo por toda a vida, tendo inclusive convidado o professor a ministrar palestras na Itália em 1923 (Menegatti 2008, p. 13-14). Numa de suas cartas ao antigo mestre, escreveu Sraffa: "Sou incapaz de expressar, em meu limitado inglês, minha completa gratidão por sua generosidade para comigo e por seus ensinamentos, com os quais aprendi muito mais do que em meus vários anos de estudo da economia 'Loriana' [referente ao economista italiano Achille Loria (1857-1943)] em Torino" (Sraffa a Foxwell, 23 de junho de 1922; consultem-se igualmente, as cartas de Sraffa números 276, 429 e 473 em Kwansei Gakuin, 2018). 
da concorrência perfeita por assumir as hipóteses irrealistas de que os produtores individuais seriam incapazes de afetar o preço de mercado e, além disso, de que os custos unitários em cada firma redundariam crescentes com o aumento da produção, suposições desenhadas, segundo ele, de modo a imprimir à teoria da oferta e da demanda uma simetria artificial. Estruturas monopolistas emergiriam, para Sraffa, de fatores inerentes ao processo competitivo. Uma interpretação mais concreta da operação dos mercados deveria levar em consideração as dificuldades de comercialização de oferta adicional sem comprometer os preços, assim como a ausência de indiferença dos consumidores entre as marcas disponíveis, segmentando a demanda em compartimentos ligados às empresas de maior porte (Sraffa, 1926) .

Quando cada uma das firmas produzindo uma mercadoria encontra-se em tal posição, o mercado geral para essa mercadoria é subdividido em mercados distintos. Qualquer firma que pretenda ir além do seu próprio mercado mediante invasão daqueles de seus competidores deverá incorrer em grandes despesas de marketing a fim de vencer as barreiras que os cercam; de outra parte, porém, no interior de seu próprio mercado e sob a proteção de sua própria barreira, cada qual usufrui posição privilegiada por meio da qual obtém vantagens que, se não em extensão, pelo menos em natureza, equivalem àquelas desfrutadas pelo um monopolista comum (Sraffa, 1926, p. 542).

Retornando a Foxwell, a partir de três palestras proferidas na Industrial Remuneration Conference, no verão de 1885, na Escócia, ele montou no ano seguinte o livro The Irregularity of Employment and the Fluctuations of Prices (1886), tratando prioritariamente da questão referente à instabilidade do emprego, por ele qualificada o pior dos males da sociedade moderna. Tendo em conta a recorrência das flutuações econômicas, Foxwell lista uma série de dificuldades delas derivadas, como a falta de proteção das classes desfavorecidas nos tempos de depressão industrial, as perdas de capital e de habilidades durante a transferência de recursos produtivos entre os setores da economia, o rastro de sofrimento deixado pela introdução da maquinaria e pela luta competitiva e, finalmente, as reduções salariais nos períodos de desemprego (Foxwell, 1886, p. 10-24).

As razões para a instabilidade do capitalismo por ele apontadas envolveriam, de uma parte, a natureza do sistema monetário vigente e, de outra, a predisposição geral da indústria moderna a sofrer perturbações devido ao avançado estágio da divisão do trabalho e de desenvolvimento do crédito. Embora não fosse um autor subconsumista tradicional, a análise dos períodos de crises por parte de Foxwell mostrou-se repleta de observações extremamente acuradas e prolíficas. Em relação ao primeiro fator, ele culpou a corrida ao ouro pelos bancos continentais como a principal causa da deficiência de dinheiro e de deflação generalizada. As reduções de preços, embora aparentemente benéficas aos trabalhadores, estariam frequentemente acompanhadas por retração nas atividades da indústria e do varejo, aumentando o desemprego. Como os custos não caem tão rapidamente quanto os preços, os lucros terminariam comprimidos pelo diferencial entre receitas e despesas, enquanto os

(9) Quanto ao debate sobre a pertinência do conceito de firma representativa de Marshall, consulte-se o simpósio de 1930 no Economic Journal envolvendo Dennis H. Robertson, Sraffa e Gerald F. Shove (Robertson; Sraffa; Shove, 1930). 
contratos de débito precisariam ser honrados com uma moeda mais valorizada, despejando assim fardo adicional nos ombros dos produtores. A segunda razão para a pressão deflacionária da época nasceria da elevada especialização da indústria, pois o menor erro de cálculo no direcionamento dos investimentos seria amplificado pela especulação e o crédito fácil, processo sempre propenso a desaguar em crise financeira (Foxwell, 1886, p. 38-56).

A indústria e o comércio têm trabalhado sob um grau de pressão anteriormente desconhecido, e a população e a riqueza aumentaram; com tudo isso, verifica-se imenso desperdício -tanto de homens quanto de materiais-, sofrimento e aflição inéditos, desvirtuamento do princípio comercial, adulteração de produtos e deterioração do bomgosto. A indústria progrediu nos seus métodos e resultados sob intensa concorrência. Não obstante, não é à tal luta anárquica que devemos o grande avanço de nossa época. Ela se distinguirá na história não tanto pelo rápido aumento na produção material, mas pelas notáveis descobertas nas ciências físicas e naturais (Foxwell, 1886, p. 71).

Paralelamente a esse diagnóstico alarmante da situação econômica dos mercados, Foxwell concebeu um complexo programa de reformas para atenuar as flutuações de preços e a instabilidade econômica geral, compreendendo uma agenda que ele indicou pelo termo "Organização". Além da já mencionada restauração do bimetalismo e do controle público dos monopólios, ele sugeriu amplo conjunto de medidas para oferecer maior transparência de informação ao público. A iniciativa envolveria a compilação, por agências oficiais, de estatísticas agregadas de produção, emprego, consumo e distribuição de renda, a serem disponibilizadas a todos órgãos públicos e privados ligados aos negócios. A especulação e a corrupção, no entendimento de Foxwell, alimentavam-se da ignorância e da desinformação, enquanto a essência da democracia consistiria precisamente na ampla publicidade dos atos, processo que tornaria o interesse público mais poderoso e supremo.

Visando minorar as oscilações industriais e a especulação, Foxwell recomendou, primeiramente, a compilação, por agências oficiais, de estatísticas agregadas de produção, emprego, consumo e distribuição de renda. Em acréscimo, indicou a necessidade de criação de algum tipo de organização, como as guildas medievais, unindo empresas de uma mesma atividade, as quais deveriam trabalhar em conjunto a fim de manter os preços estáveis, moderar a competição e regular o produto comum. Tais associações, adicionalmente, compartilhariam a responsabilidade de fornecer educação técnica e aprendizado, realizar o controle de qualidade dos produtos e punir as falsificações, buscando ainda os melhores canais de venda com o propósito de eliminação dos intermediários. Por fim, no tocante ao problema do desemprego, Foxwell sugeriu, primeiramente, a criação de uma agência do trabalho para amparar os desempregados e oferecer-lhes informações sobre oportunidades de trabalho, poupança, aposentadoria e demais assuntos de seu interesse comum. Nesse sentido, seria recomendável ainda a adoção de contratos de trabalho de longo-prazo, além da introdução de servidores permanentes nas instituições públicas como museus, hospitais e similares, de modo a reforçar a estabilidade geral do emprego (Foxwell, 1886, p. 73-90). 
Não é difícil aqui perceber que a preocupação de Foxwell com o controle dos monopólios e os efeitos perversos do desemprego encontraria significativa ressonância em Cambridge. Já em sua obra maior, Wealth and Welfare, publicada em 1912, Pigou dedicou nove capítulos ao tema dos monopólios (Pigou, 1912, caps. IX-XVII). Discorrendo sobre a ação estatal na regulação de mercados monopolistas, Pigou mostrou-se favorável a combinações entre produtores em setores com número reduzido de firmas a fim de promover a estabilidade da oferta e dos preços. Intervenção estatal voltada a incentivar a concorrência, nestes casos, resultaria unicamente em agravamento da competição desleal, eliminação de produtores e consequente contração do dividendo nacional. Antes, caberia ao Estado preservar um mínimo de concorrência potencial mediante a penalização legal de práticas como o dumping ou o boicote de monopolistas a fornecedores buscando proibi-los de negociar com empresas rivais. Assim agindo, o Estado restringiria a majoração excessiva de preços devido ao temor, por parte das firmas estabelecidas, da entrada de novos concorrentes no mercado, criando inclusive um ambiente legal adverso às práticas predatórias junto à opinião pública, como sugerido por Foxwell:

Não se deve esquecer, porém, que as leis que podem ser evadidas se as pessoas se empenharem para tanto, não o são de fato de maneira geral. Pois a mera aprovação de uma lei reage sobre a opinião pública e lança no campo da prática sustentada pela lei as potentes forças da "respeitabilidade" e da inércia. Podemos esperar, portanto, que leis dessa natureza, se cuidadosamente elaboradas, serão ao menos parcialmente bemsucedidas em seus propósitos imediatos (Pigou, 1912, p. 264).

Resultaria ocioso, nessa altura, enfatizar a importância central do volume de emprego tanto nas obras de Pigou quanto de Keynes. Relativamente a este último, em carta a Roy Harrod, datada de 30 de agosto de 1936, basta indicar como Keynes se expressa no tocante à sua evolução intelectual envolvendo o abandono da teoria clássica rumo à uma nova visão dominada pelo conceito de demanda efetiva e seu impacto sobre o nível de emprego:

Para mim, a coisa mais extraordinária, do ponto de vista histórico, consiste no completo desaparecimento da teoria da oferta e da demanda pelo produto no seu todo, ou ainda, a teoria do emprego, após ela ter sido por mais de um quarto de século o tema mais discutido em economia. Uma das minhas transições mais importantes, depois de o Treatise on Money ser publicado, foi a súbita consciência desse fato (Keynes, 1973 [1936], p. 85; itálicos no original).

Vejamos então, na próxima seção, de que maneira as reflexões de Foxwell sobre o desenvolvimento da economia política britânica no século dezenove terminariam por ressurgir de forma explícita no pensamento de Keynes a respeito da obra de Thomas R. Malthus e Ricardo.

\section{História do pensamento econômico}

A exposição mais articulada de Foxwell sobre a história do pensamento econômico encontra-se em sua longa introdução ao livro de Anton Menger, The Right to the Whole 
Produce of Labour, publicado em $1899^{10}$. Já no início, Foxwell condena o que julgava ele ser a completa desconsideração, por parte dos economistas clássicos, daqueles aspectos da ação econômica ligados à lei, aos costumes e à história. Esse estado de coisas, porém, haveria sido sacudido em suas bases pelo advento da escola histórica, que apregoava a importância da lei positiva para o progresso da sociedade. As noções de igualdade e justiça, no juízo de Foxwell, embora repelidas em certas épocas, encontram-se sempre adiante da história concreta, configurando-se em causa primária das mudanças nos hábitos, no pensamento e na legislação. Em seus próprios termos: "Poderia ser dito com igual verdade que a equidade de uma era se torna a lei da próxima. Se a lei positiva é a base da ordem, o direito ideal é o fator ativo do progresso" (Foxwell, 1899, p. xi).

A chave para a estabilidade social, segundo Foxwell, localizar-se-ia no gradual desenvolvimento das ideias sobre os direitos, bem como no concomitante avanço das instituições oriundas deste processo. A análise do direito ideal, entretanto, particularmente no campo econômico, resultaria tarefa extremamente complexa devido à circunstância de as propostas socialistas jamais haverem se materializado até então. A despeito dessa limitação, pensadores socialistas britânicos teriam tratado em minúcia da quase totalidade das moléstias da sociedade capitalista. E, não apenas isso, eles também já haveriam proposto todos os tipos imagináveis de correções da situação, como a reforma agrária, o cooperativismo, a legislação fabril, a formação de sindicatos e até mesmo a derrubada revolucionária do sistema produtivo vigente (Foxwell, 1899, p. xxv-xxix).

Fazendo uso de seu vasto domínio da literatura econômica, Foxwell analisa com desenvoltura as contribuições dos maiores pensadores sociais britânicos do final do século dezoito e grande parte do século dezenove. William Godwin (1756-1836) é apontado por ele como a fonte pioneira do movimento reformista da época, embora a sua obra mais proeminente, An Enquiry Concerning Political Justice (1793), devido à combinação singular de comunismo com anarquismo individualista, tivesse se revelado por demais ingênua para exercer apelo às mentes radicais e revolucionárias (Foxwell, 1899, p. xxvii-xxxi). William Thompson (17751833), de sua parte, é apontado como o chefe da escola socialista inglesa em vista da larga influência de seus escritos e de sua dedicação incansável ao avanço do movimento cooperativista. Apesar disso, Thompson teria pecado por ser excessivamente confiante em métodos voluntários de promoção da igualdade social, notadamente as comunidades owenitas, tão veneradas pelos críticos do capitalismo no século dezenove. A contribuição mais duradoura de Thompson ao socialismo anglo-saxão, porém, residira no seu empenho em trazer ao centro do debate econômico a questão-chave da desigualdade na distribuição de renda, particularmente na obra An Inquiry into the Principles of the Distribution of Wealth (1824) (Foxwell, 1899, p. xxxviii-xlvii; sobre o pensamento de Thompson, veja-se Cinelli; Arthmar, 2018).

(10) Para as opiniões do professor sobre Marshall, Jevons, Cunningham e o jovem Keynes, consulte-se Foxwell (1884, 1913, 1919b). 
Já o fundador do cooperativismo britânico, Robert Owen (1771-1858), é enaltecido pelo professor como o homem que efetivamente logrou arrancar o ideal socialista dos livros e levá-lo às ruas, tornando-o a base de ampla agitação popular. Todas as conquistas da vida social britânica do século dezenove, desde a educação popular ao sindicalismo, passando pelo cooperativismo e a legislação fabril, teriam, no juízo do Foxwell, se materializado por influência de Owen (Foxwell, 1899, p. 1xxix-lxxxvii) ${ }^{11}$. O tema central da introdução ao livro de Menger, entretanto, revolve em torno da concepção de que embora o filantropo gaulês viesse a se afigurar o personagem chave a incutir o ideário reformista na mente popular, Ricardo teria sido aquele que efetivamente fornecera o arcabouço intelectual à retórica socialista que lhe seguiu. Isso porque quase todos os reformadores ingleses do século dezenove, mesmo os revolucionários, teriam se apoiado naqueles trechos dos escritos de Ricardo sobre o antagonismo de classes nascido da oposição direta entre salários e lucros ${ }^{12}$. As instâncias em que Foxwell repete essa interpretação são diversas, mas por razões de espaço reproduz-se aqui apenas uma delas para que se tenha noção mais precisa de seu argumento:

Foi Ricardo, não Owen, quem forneceu de fato a inspiração para o socialismo inglês. Essa influência foi indireta e negativa, mas é inegável. Thompson e os demais aceitaram como corretas as deduções desafortunadas e forçadas de Ricardo, citando-o como autoridade inquestionável. Percebendo que certas de suas conclusões eram contrárias ao seu senso de justiça, e assumindo que ele tinha aceito as condições existentes da sociedade como suas premissas, eles naturalmente dirigiram todas as forças de seu ataque a tais condições. Essa foi a real origem intelectual do socialismo revolucionário, e é por essa razão que o chamei de ricardiano (Foxwell, 1899, p. lxxxiii; veja-se também xl, xli, lvi fn.1, lxxi).

Foxwell conclui indicando aquela que, segundo ele, seria a contradição maior do pensamento socialista, a saber: embora o trabalhador devesse ser o proprietário da totalidade do seu esforço por uma questão de justiça, num sistema dominado pela divisão do trabalho torna-se impossível definir o quanto cada qual contribuiu efetivamente no conjunto do processo produtivo. Essa dificuldade conceitual e prática, explica Foxwell, somente poderia ser superada por um arranjo social no qual o conjunto da produção pertencesse à totalidade dos trabalhadores. Por esse motivo, os discursos socialistas terminariam por convergir, invariavelmente, ao objetivo final da igualdade de todos sob o comunismo. A única alternativa concreta a uma mudança revolucionária de tal teor, preconiza Foxwell, envolveria a gradual implementação de legislação social e tributação progressiva de modo a repartir de forma mais justa as rendas auferidas por aquelas parcelas da sociedade sem papel produtivo concreto (Foxwell, 1919, p. cv-cx).

(11) Sobre outros socialistas britânicos do século dezenove como Thomas Hodgskin (1787-1869) e John Francis Bray (1809-1897), veja-se Foxwell (1919, p. lv-lxxi).

(12) Estudos modernos, entretanto, evidenciam que grande parte da literatura socialista do século dezenove na Inglaterra esteve, com efeito, sob a influência maior dos trabalhos de Adam Smith (Thompson, 2002, p. 82-110) e de Robert Owen (Claeys, 1987, p. 130-165). Nesse ponto, Foxwell não levou em consideração devida quão difícil era, mesmo para os ricardianos mais leais, dominar os detalhes da intricada teoria do valor ricardiana (a esse respeito, consulte-se Peach, 2009, p. 145-240). As teses de Smith e Owen, ao contrário, apresentavam maior apelo ao senso comum do que as abstrações de Ricardo e, por conseguinte, detinham maior capacidade de entendimento e difusão entre largos segmentos da sociedade britânica. 
Marshall, para quem Ricardo fora um economista brilhante na análise da moeda e do comércio exterior, não deixou de apontar a omissão da doutrina ricardiana relativamente aos interesses das classes trabalhadoras e ao impacto negativo do pauperismo sobre as condições de produção da riqueza (Marshall, 1920 [1890], p. 762-764). Keynes, nesse aspecto, porém, parece ter sofrido maior influência de Foxwell, porquanto a sua condenação de Ricardo mostrou-se bem mais ampla, abrangendo tanto o irrealismo do método quanto à teoria em si. Keynes insurgiu-se principalmente contra aquilo que considerou o conteúdo inverossímil e abstrato da Lei de Say, fundamental no esquema ricardiano para assegurar que a elevação dos salários constituísse a única causa efetiva de redução nos lucros. O mesmo fenômeno de queda na rentabilidade dos capitais, contudo, poderia nascer de uma deficiência geral de demanda oriunda de apego excessivo à parcimônia e consequente redução do consumo, como sustentado de maneira mais razoável, na perspectiva de Keynes, por Malthus. Em suas notas sobre a biografia do reverendo, após revisar as numerosas cartas entre ele e Ricardo, então já compiladas por Sraffa, Keynes assinalou, como repetiria adiante na Teoria Geral: "Não se pode ler essa correspondência sem o sentimento de que o total bloqueio da linha de argumentação de Malthus e de completo domínio, por mais de cem anos, daquela defendida por Ricardo, configurou absoluto desastre para o progresso da ciência econômica" (Keynes, 1933, p. 140-141; veja-se também 2013 [1936], p. 32-34).

\section{Considerações finais}

De modo geral, pode-se caracterizar Foxwell como um economista de transição, num período de rápido declínio da tradição clássica e ascensão das escolas marginalista e historicista. Ele sempre revelou o melhor de si quando utilizava a sua larga erudição e agudo intelecto para apontar as debilidades dos cânones da economia política tradicional. As suas críticas à concepção clássica do laissez faire, a especificação detalhada da natureza destrutiva da livre ação dos mercados e o reconhecimento dos custos sociais da luta competitiva apresentavam-se por demais convincentes para não influenciar os seus contemporâneos. Tais ideias encontrariam caminho nos escritos dos economistas de Cambridge mais influentes nas primeiras décadas do século vinte, como Keynes, Pigou e Sraffa, preocupados com as limitações da concorrência e os efeitos perversos do desemprego. De fato, o interesse de Foxwell nas flutuações industriais e consequente impacto sobre os mais vulneráveis reverberou por toda a tradição de Cambridge, inclusive na definição das condições de melhoria do bemestar adiantadas por Pigou, cobrindo o aumento do dividendo nacional, a distribuição mais igualitária da renda e o combate às flutuações industriais (Pigou, 1912, p. 20-32).

No aspecto propositivo, as intuições de Foxwell sobre a natureza dos monopólios na sociedade moderna mostraram-se essencialmente acuradas, embora não aprofundadas o suficiente para direcioná-lo a uma visão mais consistente da ação de tais empresas e de como proceder para regular efetivamente esse tipo de estrutura de mercado. O progressivo distanciamento do professor da teoria pura, assim como o seu crescente apego à história, fizeram por remetê-lo ao passado na busca de soluções para os problemas de seu tempo. 
Aprisionado entre essas tendências conflitantes, ele somente logrou conceber a restauração do bimetalismo e a introdução de uma forma moderna das guildas medievais como remédios mais apropriados para lidar com a instabilidade monetária e econômica que contemplava. Falando rigorosamente, ele jamais cogitou o abandono integral do substrato metálico da moeda ou mesmo uma política fiscal ativa como meios de combater o desemprego. Apesar de tais restrições, a qualidade analítica e empírica da contribuição de Foxwell aos debates econômicos da época, haurida nos autores panfletários do passado, não parece ter recebido justa atenção na literatura econômica moderna.

\section{Referências bibliográficas}

ARTHMAR, R.; McLURE, M. Cambridge theories of welfare economics. In: CORD, R. A. (Ed.). The Palgrave Companion to Cambridge Economics. London: Palgrave Macmillan, 2017. p. 51-71.

ASLANBEIGUI, N.; OAKES, G. Arthur Cecil Pigou. Houndmills: Palgrave Macmillan, Great Thinkers in Economics, 2015.

BACKHOUSE, R. E.; NISHIZAWA, T. (Ed.). No wealth but life: welfare economics and the welfare state in Britain, 1880-1945. Cambridge: Cambridge University Press, 2010.

BONAR, J. H. S. Foxwell. Journal of the Royal Statistical Society, v. 99, n. 4, p. 837-841, 1936.

BOUCHER, D. The British idealists. Cambridge: Cambridge University Press, 1997.

BOWLEY, A. L.; FREMAN, R. D. Foxwell, Herbert Somerton (1849-1936). Oxford Dictionary of National Biography, Oxford, Oxford University Press, 2004.

CANNAN, E. The Paper Pound of 1797-1821. A reprint of the Bullion Report. London: P. S. King \& Son, 1919.

CINELLI, C. L. K.; ARTHMAR, R. The debating tradition in Britain and the new political economy: William Thompson and John Stuart Mill at the London Co-operative Society in 1825. Nova Economia, v. 28, n. 2, p. 609-636, 2018.

COASE, R. H. The appointment of Pigou as Marshall's successor. Journal of Law and Economics, v. 15, n. 2, p. 473-485, 1972.

COATS, A.W. The appointment of Pigou as Marshall's successor: Comment. Journal of Law and Economics, v. 15, n. 2, p. 487-495, 1972.

COATS, A. W. The historic reaction in English political economy 1870-90. Economica, New Series, v. 21, n. 82, p. 143-153, 1954.

CLAEYS, G. Machinery, money and the millennium. From moral economy to socialism, 18151860. Princeton: Princeton University Press, 1987. 
Rogério Arthmar

CUNNINGHAM, W. Political economy as a moral science. Mind, v. 3, n. 11, p. 369-383, 1878 .

FETTER, F. W. The development of British monetary orthodoxy 1797-1875. Cambridge, Massachussets: Harvard University Press, 1965.

FOXWELL, H. S. Introduction. In: JEVONS, W. S. Investigations in currency and finance. London: Macmillan, 1884. p. xix-xliv.

FOXWELL, H. S. Irregularity of employment and fluctuations of prices. Edinburgh: Cooperative Printing Company, 1886.

FOXWELL, H. S. The economic movement in England. The Quarterly Journal of Economics, v. 2, n. 1, p. 84-103, 1887.

FOXWELL, H. S. Mr. Goschen's currency proposals. The Economic Journal, v. 2, n. 5, p. 139$156,1892$.

FOXWELL, H. S. Introduction. In: MENGER, A. The right to the whole produce of labour. London: Macmillan, 1899.

FOXWELL, H. S. The Goldsmiths' Company's Library of Economic Literature. In: HIGGS, H. (Ed.). Palgrave's Dictionary of Political Economy. London: Macmillan, 1908. p. 720-722.

FOXWELL, H. S. Preface. In: ANDRÉADÈS, A. M. History of the Bank of England. London: P. S. King \& Son, 1909.

FOXWELL, H. S. J. M. Keynes' Indian Currency and Finance. (Book review). The Economic Journal, v. 23, n. 92, p. 561-572, 1913.

FOXWELL, H. S. Papers on current finance. London: Macmillan, 1919a.

FOXWELL, H. S. Obituary. Archdeacon Cunningham. The Economic Journal, v. 29, n. 115, p. 382-395, 1919b.

FREEDEN, M. The new liberalism: an ideology of social reform. Oxford: Clarendon Press, 1986.

GROENEWEGEN, P. A soaring eagle: Alfred Marshall 1842-1924. Aldershot: Edward Elgar, 1995.

HARCOURT, G. What is the Cambridge approach to economics? In: HARCOURT, G. On Skidelsky's Keynes and other essays. London: Palgrave Macmillan, 2012 [2007]. p. 219-239.

HUME, L. J. The gold standard and deflation: issues and attitudes in the 1920s. In: POLLARD, S. (Ed.). The gold standard and employment policies between the wars. London: Methuen, 1970. p. 122-145.

JEVONS, W. S. The theory of political economy. $3^{\text {rd }}$ ed. London: Macmillan, 1871. 
KEYNES, J. M. The economic consequences of Mr. Churchill. In: KEYNES, J. M. Essays in persuasion. London: Macmillan, 1933 [1925]. p. 244-270.

KEYNES, J. M. The end of laissez faire. Marseille: Agone, 1999 [1926].

KEYNES, J. M. The end of the gold-standard. In: KEYNES, J. M. Essays in persuasion. London: Macmillan, 1933 [1931]. p. 288-294.

KEYNES, J. M. Robert Malthus. The first of the Cambridge economists. In: KEYNES, J. M. Essays in biography. London: Macmillan, 1933. p. 95-149.

KEYNES, J. M. Herbert Somerton Foxwell. The Economic Journal, v. 46, n. 184, p. 519-614, 1936.

KEYNES, J. M. The general theory of employment, interest and money. Cambridge: Cambridge University Press for The Royal Economic Society. In: ROBINSON, A.; MOGGRIDGE, D. (Ed.). The collected writings of John Maynard Keynes, 2013 [1936]. v. VII.

KEYNES, J. N. The scope and method of political economy. $2^{\text {nd }}$ ed. London: Macmillan, 1897 [1890].

KOOT, G. M. H. S. Foxwell and English historical economics. Journal of Economic Issues, v. XI, n. 3, p. 561-586, 1977.

KOOT, G. M. Foxwell, Herbert Somerton (1849-1936). In: EATWEL, J.; MILGATE, M.; NEWMAN, P. (Ed.). The New Palgrave: a dictionary of economics. $1^{\text {st }}$ ed. London: Palgrave Macmillan, 1987. p. 3672-3674.

KWANSEI Gakuin University Library. Foxwell Papers, cartas 50, 85, 97, 261, 276, 386, 429, 473. Disponível em: https://library2.kwansei.ac.jp/e-lib/keizaishokan/foxwell/index.html. Acesso em: 20 set. 2018.

MALONEY, J. The professionalization of economics. Alfred Marshall and the dominance of the orthodoxy. New Brunswick: Transaction, 1991.

MARSHALL, A. vThe present position of economics. In: PIGOU, A. C. (Ed.). Memorials of Alfred Marshall. London: Macmillan, [1885] 1925. p. 152-174.

MARSHALL, A. Principles of economics. London: Macmillan, 1920 [1890].

MENEGATTI, M. Piero Sraffa. An Italian economist. Saarbrücken: Verlag, 2008.

MINTS, L. W. A history of banking theory in Great Britain and the United States. Chicago: The University of Chicago Press, 1945.

MYINT, H. Theories of welfare economics. London: Longmans, Green, 1948.

NICHOLSON, J. S. Papers on current finance. (Book review). The Economic Journal, v. 29, n. 115 , p. $317-323,1919$.

PEACH, T. Interpreting Ricardo. Cambridge: Cambridge University Press, 2009. 
PIGOU, A. C. Wealth and welfare. London: Macmillan, 1912.

PIGOU, A. (Ed.). Memorials of Alfred Marshall. London: Macmillan, 1925.

RICARDO, D. The high price of bullion. In: SRAFFA, P. (Ed.). The works and correspondence of David Ricardo. v. III: Pamphlets and Papers 1809-1811, Indianapolis: Liberty Fund, 2004 [1809]. p. 47-127.

ROBERTSON, D. H.; SRAFFA, P.; SHOVE, G. F. Increasing returns and the representative firm. The Economic Journal, v. 40, n. 157, p. 79-116, 1930.

ROGERS, R. R. The Kress Library of business and economics. The Business History Review, v. 60. n. 2, p. 281-288, 1986.

SCHUMPETER, J. A. History of economic analysis. London: George Allen \& Unwin, 1963.

SHOVE, G. F. The place of Marshall's principles in the development of economic theory. The Economic Journal, v. 52, n. 208, p. 294-329, 1942.

SKIDELSKY, R. John Maynard Keynes. v. 2: The economist as Saviour 1920-1937. New York: The Penguin Press, 1994.

SRAFFA, P. The laws of returns under competitive conditions. The Economic Journal, v. 36, n. 144, p. 535-550, 1926.

THOMPSON, N. W. The people's science. The popular political economy of exploitation and crisis 1816-34. Cambridge: Cambridge University Press, 2002. 